\title{
El paso de negra en el Coloquio de Gila, de Lope de Rueda, y otras negras en el teatro del siglo XVI
}

\section{The Interlude of the Black Woman in the Coloquio de Gila by Lope de Rueda, and Other Black Women in Sixteenth-Century Spanish Theater}

\section{María Luisa Lobato}

Universidad de Burgos

ESPAÑA

mlobato@ubu.es

[Hipogrifo, (issn: 2328-1308), 5.1, 2017, pp. 305-325]

Recibido: 24-11-2015/ Aceptado: 17-12-2015

DOI: http://dx.doi.org/10.13035/H.2017.05.01.20

Resumen. El Coloquio de Gila, de Lope de Rueda, dado a conocer hace menos de una década, presenta la figura de la negra Sofía con una serie de rasgos identificativos. Algunos de ellos se encuentran ya en textos poéticos con fuerte carga de dramaticidad escritos a fines del siglo XV, como los de Anrique de Mota y Rodrigo de Reinosa, pero va a ser en el siglo XVI cuando el tipo de 'negra' se presente en las obras literarias de Jaime de Huete, Feliciano de Silva, Gaspar Gómez de Toledo, Gil Vicente y Diego Sánchez de Badajoz. Un repertorio lo suficientemente amplio para examinar el tipo de la negra y establecer los rasgos de este personaje a partir de los textos literarios que la presentan.

Palabras clave. Mujer, teatro, entremés, negra, siglo XVI, Renacimiento, honor, raza, Lope de Rueda, Anrique de Mota, Rodrigo de Reinosa, Jaime de Huete, Feliciano de Silva, Gaspar Gómez de Toledo, Gil Vicente, Diego Sánchez de Badajoz .

Abstract. The Coloquio de Gila by Lope de Rueda, which came to light less than a decade ago, presents the figure of the black woman Sofía with a number of iden- 
tifying characteristics. Some of these characteristics are already found in poetic texts that contain a noticeable element of dramatisation and were written towards the end of the fifteenth century, such as those by Anrique de Mota and Rodrigo de Reinosa. But it is in the sixteenth century that the 'black woman' character type appears in literary works by Jaime de Huete, Feliciano de Silva, Gaspar Gómez de Toledo, Gil Vicente and Diego Sánchez de Badajoz. These works constitute a sufficiently wide repertoire to examine the black woman character type and to establish the characteristics of this type on the basis of the literary texts in which she appears.

Keywords. Woman, Theater, Interlude, Black Race, 16Th Century, Renaissance, Honour, Race, Lope de Rueda, Anrique de Mota, Rodrigo de Reinosa, Jaime de Huete, Feliciano de Silva, Gaspar Gómez de Toledo, Gil Vicente, Diego Sánchez de Badajoz.

Cuando la negra Sofía creada por Lope de Rueda pide a la pastora Gila y a su padre, cabañero, que le besen la mano, no se trata de un gesto accidental. La solicitud llega después de que la negra exponga su prosapia familiar y presente ante el público del siglo XVI una interacción racial pionera en la poesía y en el teatro de 'negras', que sirve de gozne entre el ensimismamiento de los personajes 'morenos' de la lírica de los siglos XV y XVI y la inclusión del personaje 'negro/negra' en el teatro del XVII español. Hay, en efecto, algunos protagonismos destacados de personajes negros en las comedias del Barroco, que sitúan al personaje de color en franco parangón con el blanco, instaurando una especie de 'negrofilia' en la literatura, que debía tener escasa presencia en la vida social de su época.

\section{HACIA EL ORIGEN DEL TIPO DE LA 'NEGRA' EN EL TEATRO DEL SIGLO XVI}

Mucho se ha discutido sobre la construcción del personaje del negro, entre la realidad de la sociedad española de su tiempo y la ficción literaria'. Negros y negras los hubo, desde luego, en calidad de subalternos de los blancos, la mayor parte de ellos nombrados como esclavos. Su presencia en la sociedad española está bien documentada en el periodo que aquí interesa. Conocemos noticias de negros entreverados con amos de distintos oficios en la vida española de los siglos XVI y XVII, entre otros, hombres y mujeres involucrados en el oficio teatral. Un caso conocido es el de Jerónimo Velázquez, el autor y empresario de teatro más importante en España entre 1574-1598, que el 5 de junio de 1585 compró una esclava de veinte años, negra atezada, a un mercader de lencería, así como también a una hija suya llamada Catalina de Santos. O, ya en el XVII, hay constancia de que la famosa actriz Micaela de Luján tenía una criada negra a la que le falleció un hijo pequeño el

1. Es muy numerosa la literatura al respecto; ver, entre otros, Andújar Castillo, 1999; Baranda Leturio, 1989; Castellano, 1961; Cortés López, 1989; Fra Molinero 1995 y 2014; Granda, 1978; Lawrence, 2005; Profeti, 2005; Santos Morillo, 2011; Stoichita, 2002; Swiadon Martínez, 2006 y Weber de Kurlat, 1962 y 1963. 
24 de septiembre de 1612. Estos ejemplos pueden servir de muestra de la cercanía de esclavas negras no sólo en las calles por las que todos se movían sino de forma específica en las casas de los artistas y de los hombres y mujeres de teatro.

Podría parecer obvio afirmar que el personaje de la negra pasó de la vida a la literatura y se mantuvo en la realidad social y en la ficción al mismo tiempo. Sin embargo, muchas preguntas surgen a la luz de esta connivencia, entre ellas la tan tratada de la trasposición a la obra literaria de los rasgos y lenguaje de un tipo social. Cabría interrogarse también si algún miembro de estos grupos pudo tener cierto protagonismo en la representación de este tipo de personaje en el teatro, aunque parece improbable, al menos en su primera época. Y, en cuanto a la poesía de negros, es posible plantear hasta qué punto resulta legítimo inferir que parte de la que se ha conservado es una transliteración de la recitada y cantada por ellos. A raíz de estas consideraciones, surgen varias posibilidades en torno a la composición de las piezas poéticas y teatrales protagonizadas por negros y negras que han llegado hasta nosotros. Nos interesarán ahora aquellas escritas por blancos en las que se presenta el personaje de la negra con un lenguaje que parece cercano al que se podía oír por las calles de España.

La crítica ha analizado estas composiciones desde puntos de vista muy variados, entre otros a partir de una visión sociológica de este tipo de composiciones, realizada en fechas recientes tomando como punto de partida presupuestos de nuestro tiempo y no siempre desde el análisis de los textos conservados. Pero interesaría observar la evolución de la literatura del negro ab intra, a partir de los mismos escritos literarios que los muestran, pues es posible apreciar una consolidación de su papel y de sus funciones desde su aparición en la poesía el siglo XV hasta su desarrollo total en el teatro del XVII. No será posible aquí llegar hasta el periodo Barroco, pero confiamos en que el análisis de textos del siglo XVI facilite la tarea a nuevos enfoques del siglo siguiente. Por otra parte, este tipo cómico trasvasa géneros literarios, sin que sea posible tampoco olvidar la vertiente musical y bailada de las composiciones que protagoniza. Coincide en algunos de estos aspectos con otras modalidades literarias, como los protagonistas de la jácara, a la que hemos dedicado dos monografías ${ }^{2}$.

El tipo que nos interesará ahora será el de la negra en el teatro, si bien somos conscientes de que analizar su presencia sólo podrá hacerse en un número limitado de obras, pues no son muchas las escritas en el XVI que incorporan este personaje. Partiremos de un par de obras poéticas con buena dosis de dramaticidad, como son las de Anrique de Mota titulada D'Anrique da Mota a um Créligo sobre ũa pipa de vino que se Ihei foi polo chão, e lamentava-o desta maneira (1495?) y de Rodrigo de Reinosa (1516-1520?) en su poema Mangana, mangana y Coplas a los negros y negras. Se tratarán después piezas dramáticas del XVI, en concreto las de Jaime de Huete: Tesorina (1528-1535), Feliciano de Silva: Segunda Celestina (1534), Gaspar Gómez de Toledo: Tercera parte de la tragicomedia de Celestina (1536), Gil Vicente: Floresta d'Engaños (1536), Diego Sánchez de Badajoz (1525-

2. Lobato, 2014 y Lobato y Bègue (ed.), 2014. 
1547): Farsa teologal, Farsa de la hechicera, Farsa de la ventera y Lope de Rueda: Coloquio de Gila y Eufemia (a. 1566).

Conviene trazar de forma breve su itinerario para comprender por qué protagoniza algunos de los pasajes más jocosos de la dramaturgia del XVI. Bien podemos partir de la negra Sofía, en el coloquio de Gila escrito por Lope de Rueda, que en 2006 pudimos conocer gracias al trabajo de Pedro Cátedra. La negra protagoniza un breve paso en prosa de 115 líneas en la edición por la que citamos, que culmina en un pasaje cantado el cual se intercala casi al final de la pieza, formado por 28 versos. Si bien su contenido y personajes se encuentran imbricados con la acción total del coloquio de Gila, el texto es desglosable y se presenta como un intermedio cómico en boca de Gila:

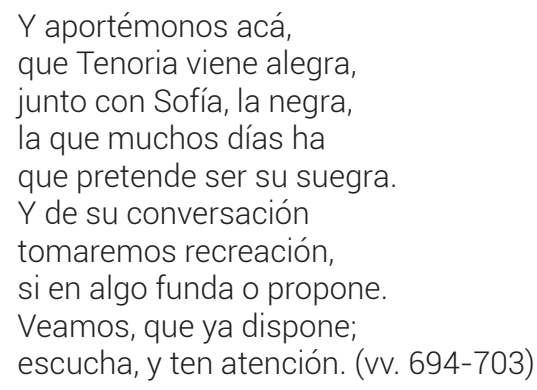

Este verbum dicendi precede la entrada en escena de la negra Sofía y de Tenoria, que llevan el peso del coloquio, aunque sin estar solas en escena, pues Gila y su padre Anselmo se encuentran apartados e intervienen en la segunda parte del mismo. Varios motivos recorren este paso: el matrimonio de la negra Sofía con un blanco de profesión infamante: verdugo, en el que muestra su orgullo por la ceremonia y los padrinos. La cierta altivez de la negra que no duda en pedir que le besen la mano Gila y su padre, aun manifestando su conciencia de que habrá oposición: «Besame la mano bosamercé, y acata bos, siñora Gila, con siñor, besame la mano también, aunque no quieras» (I. 43-45) ${ }^{3}$ y, de nuevo, para terminar el pequeño paso: «Besame la mano bosa mercé» (I. 114). También resulta reiterativa su vanidad de ser hermosa, no por creencia propia, sino porque se lo dice Gila: «Cadaldía te nos paras más hermosa» (I. 50-51) y ella asevera en la respuesta que es opinión general: «No sé, toro mundo me ro rize de aquestas mis fremosuras» (l. 52-53) y «ma formosura toro mundo la coricias» (I. 61). Y si sospechábamos la ironía en esta 'hermosura de negra', también parecen confirmarla los pasajes que siguen inmediatamente a éste, en los que la negra dice tener calenturas (I. 54) y estar ahojada (I. 57). Por último, está presente también el motivo de la buena voz que se cita como característica de esta raza. Le pregunta Gila: «itiéneste todavía la boz que solías?» (I. 102-103) y, aunque la respuesta suena a captatio benevolentiae: «Peor cinqüenta mil veces» (I. 104), nada le detiene en su canto y baile del romance deturpado La niña de Gómez Arias (vv. 705-731). Insertas estas piezas en tipos y situaciones del

3. El texto combina prosa y verso. Cuando se cita la prosa, se da la numeración de la línea. 
folklore, la prevaricación lingüística en el recitado de poemas célebres es un rasgo tipificado en la construcción de estos pasajes.

Los motivos insertos en la obra de Rueda a los que se ha hecho breve referencia en el párrafo anterior no son nuevos en la literatura en castellano con personaje negro, antes bien, tienen una tradición que los inserta en una veta de gran rentabilidad. Se ha solido citar a Rodrigo de Reinosa como primer autor poético de nombre conocido que incorporó este personaje a la poesía en castellano en el periodo 1516-1520?. En el camino que conduce de la lírica al teatro, se encuentra su diálogo en verso ambientado en Sevilla, con el título Comiençan unas coplas a los negros y negras ${ }^{4}$. No es su única composición de 'negro', pero la titulada Mangana, mangana, de la que el subtítulo de época señala que "se ha de cantar al tono de guineo», se limita a presentar la figura y quejas del personaje negro en relación con su amo, sin que avance en dramaticidad durante sus 26 versos $^{5}$.

Mucho más interesantes son las Coplas a los negros y negras de Reinosa ya citadas. En ellas el negro mandinga, llamado Jorge, y Comba, la negra de Guinea, desarrollan en poco más de 80 versos un encuentro en el que no falta el orgullo de la negra guineana, de extracto regional inferior al que tenían los territorios islamizados Gelofe o Mandinga ${ }^{6}$, de los que procede su compañero negro. Adelanta respecto al texto posterior de Rueda la figura de la negra orgullosa de sí misma y, al parecer, deseada por dos hombres, que no duda de su valía. No sólo Comba muestra vanidad de su apariencia externa, sino que el poema se inicia con la presunción de la riqueza alimentaria de su tierra frente a la de su pretendiente, lo cual no debía responder a la realidad:

$$
\begin{aligned}
& \text { A mí llamar Comba, de terra Guinea, } \\
& \text { y en la mi terra comer buen cangrejo } \\
& \text { y allá en Gelofe, do tu terra sea, } \\
& \text { comer con gran hambre caravaju vejo, } \\
& \text { cabeça de can, lagartu vermejo, } \\
& \text { por do tú andar muy muito fambrento, } \\
& \text { don puto negro caravayento. (vv. 5-11) }
\end{aligned}
$$

La disputa entre ambos no se reduce únicamente a la calidad del alimento de sus tierras respectivas sino que la altivez de la negra le lleva a establecer un segundo enfrentamiento, esta vez a propósito de su capacidad para el canto y baile: «Saber mí cantar el dulce undul, / maagana tambén quando me contento» (vv. 23-24). El orgullo viene, además, de su condición de mujer amada por varios hombres, pues espeta a su pretendiente Jorge la existencia de un enamorado llamado Grisolmo que la tiene atendida de sobra:

A mí tener yo otro guardián que dar a ti, vós, bon fogón barel, 
que dar a mí muito pedaso de pan

y bona melcocha y turrón de mel. (vv. 46-49)

Vanidosa también de su situación social, no se achanta ante la presentación que le hace Jorge - esta vez inicia él el argumento- de ser buen negro, criado por un obispo (v. 53) y hombre que se mueve en la corte (v. 54), sin que sepamos más detalles. Ante este alarde, la negra Comba asegura haber sido criada por un corregidor (v. 78) y tener una ama a la que acompañar (v. 79), todo lo cual le sirve para despreciar al negro Jorge.

No deja de sorprender la adscripción a la corte que da ese personaje y es que, entre los más finos análisis del marco en que surgieron estas figuras dramáticas, destaca el de la dimensión bufonesca del tipo del negro que hizo Fra Molinero ${ }^{7}$ y que recoge Puerto Moro $^{8}$. Sin perder de vista la posible poligénesis que defiende Russel $^{9}$, no parece descabellado pensar que el negro/negra literarios, como otros tipos cómicos, se insertaron en el teatro representado ante diversos públicos, entre los que estaba -sí- el popular y callejero, pero también el público de las pequeñas cortes de fines del siglo XV, que tenían como solaz estas piezas poéticas, parateatrales y teatrales insertas en sus festejos, entre los que no faltaban banquetes y bodas. Una prueba más tardía de ello lo tenemos en la Floresta de engaños de Gil Vicente, de la que consta su representación en 1536 ante el rey don Juan III de Portugal, obra en la que se encuentra el llamado por Tobar entremés de La negra 'paneteira', con la burla a un juez disfrazado de criada/esclava negra, pieza que se tratará más tarde.

Decimos esto porque, en efecto, no pocas de estas obritas en las que existe el personaje del negro y/o de la negra incrustan en su contenido referencias metapoéticas o metateatrales, que permiten atisbar un juego de espacio, tiempo y circunstancias entre el contexto poético o teatral y el escénico de la realidad. Por ejemplo, ya sólo en los dos casos vistos de la poesía de Reinosa, las quejas del negro anónimo que protagoniza Mangana, mangana en relación con su amo, bien podrían hacer reír en ambientes populares y refinados por igual. En cuanto a la afirmación del negro Jorge en las Coplas a los negros y negras de que es hombre que se mueve por la corte: «a mí andar en Corte» (v. 54), tras afirmar que es «de obispo criado» (v. 53), nos deja la duda de si se trata de una manifestación de vanidad con la que trata de ganarse a la displicente negra Comba o es un 'guiño' a sus espectadores cortesanos, que bien sabían de la presencia de bufones y criados negros en sus casas. 


\section{LA NEGRA COMO TIPO LITERARIO. ALGUNOS DE SUS RASGOS IDENTIFICATIVOS}

\section{La negra defensora de su honra}

En la construcción de negras como personajes poéticos se encuentra ya a fines del siglo XV (1495?) la obra de Anrique da Mota, autor portugués de quien nos llegó su poema titulado D'Anrique da Mota a um Créligo sobre ũa pipa de vino que se Ihei foi polo chão, e lamentava-o, incluido en el Cancionero General de García de Resende $^{10}$. Aunque se trata de un texto en verso, tiene fragmentos dialogados a través de los cuales se puede ver tanto la personalidad que se dibuja del clérigo que protagoniza las quejas en el poema como la de su criada negra -no sabemos si esclava- a la que trata de culpar sin éxito, puesto que ella toma su propia defensa. En el texto hay un inicio de dramatización en estilo directo que se recoge en algunas de las estrofas, el cual se completa por el indirecto de otras, en las que seguimos sabiendo la reacción de la mujer negra. De hecho, una breve acotación entre los vv. 11-12, indica: «Fala con a ssua negra» y comienza lo más vivo del diálogo entre el protagonista clérigo que acusa a su sierva negra de haber echado a perder el vino. Ella se defiende ante los ataques de su señor que quiere pegarla y aun matarla si no calla, diciendo que llamará en su apoyo al juez y a un sacristán:

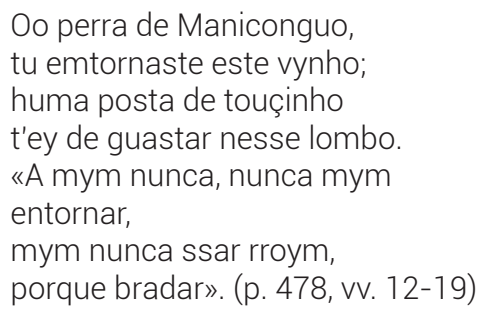

Los siguientes versos transcurren ya en estilo indirecto en boca del clérigo protagonista, pero no se pierde la fuerza del enfrentamiento entre ambos y la inclusión de quienes escuchan en esta acción casi dramática (vv. 7-15, p. 479). Y aún acusa a la criada negra de mentirosa, suponiendo que inventará ante sus defensores mentiras sobre las relaciones sexuales que mantiene con él, lo que dañaría la reputación del clérigo:

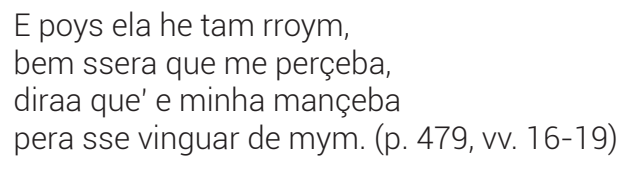

Va a ser únicamente el temor al qué dirán el que haga reflexionar al clérigo sobre la acusación que hacía de su sierva. Retrocede ante las consecuencias, pues la sabe inocente, y decide tomar sobre sí toda la responsabilidad (vv. 25-33, p. 479). La pieza transcurre con diálogos entre el clérigo y otros personajes. Será el juez

10. Sigo la edición de 1848 digitalizada por la Biblioteca Nacional de España: < http://bdh-rd.bne.es/ viewer.vm?id=0000004782\&page $=1>[9 / 1 / 2017]$. 
quien trate de calmar su desesperación, la cual le lleva hasta amenazar con el suicidio:

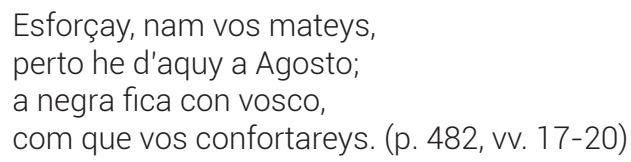

La piececita muestra, por tanto, la reacción de una sierva negra ante las acusaciones injuriosas de su amo. Lejos de temer su reacción, esta mujer innominada amenaza no sólo con su defensa personal sino con terminar con la fama de su amo clérigo a través de una mentira sobre su actividad sexual. Sólo esta amenaza en capaz de hacer reaccionar al señor injusto y le lleva a reconocer su culpa en la pérdida del vino.

La misma actitud defensiva puede verse en la criada negra de la Farsa teologal de Sánchez de Badajoz, a pesar de que comienza siendo la receptora de improperios por parte de varios personajes. En primer lugar del pastor, que la tilda de "negra maldita» (v. 781), «negra de azabache» (v. 786) y «puta guinea» (v. 1447), pero es en especial a su amo, soldado brutal, al que se presenta desde la acotación previa como violento: «Aquí entra el soldado, señor de la negra, muy feroz; y ella tras él llorando. Y ase de salir fuera del tablado la negra cuando él riñe con ella» (acot. entre vv. 800-801). Aun estando ausente, recibe los insultos de su amo: «Esta negra es del diablo» (v. 803), «ladrona» (v. 809), «tonta, lebrona» (v. 812). La mujer se enfrenta a algunos de estos improperios verbales y acaba la obra con su ataque físico al pastor, que con dificultad se libra de ella en una escena de corte entremesil. No deja de sorprender al espectador de hoy el modo en que la función cómica del personaje se aliaba en la época con la expresión de la violencia.

\section{La negra acompañante de su ama}

La función de acompañante en cuanto esclava es una de las creaciones de Sánchez de Badajoz en la farsa titulada La ventera. Aunque su acción no se precisa en la introducción que recita el pastor que abre la obra, no tarda en aparecer. Su presencia en escena llega justo a continuación y junto a su ama, una ventera en muy mala situación económica, la cual dice estar «triste, amohatrada, / empeñada y adeudada, / ques para mí gran afrenta» (vv. 82-84), situación que planea solucionar con engaños a sus clientes. Tras presentar su estado e intenciones, llega el vocativo a la esclava y el reparto de tareas (vv. 89-95). Y, en efecto, la negra está dispuesta a colaborar en la buena marcha del negocio, pero no a cualquier precio. Cuando su ama se propone robar a un pobre que ha llegado a dormir en la venta, la negra se niega a intervenir:

VENTERA

Yo lo he de asir

NEGRA

No reuitas. 


\begin{tabular}{|c|c|}
\hline VENTERA & $\begin{array}{l}\qquad \text { ¡Calla, calla!, } \\
\text { yo le he de asir la morralla. } \\
\text { ¿Si podré, sin me sentir? } \\
\text { Acá los tien ensilados. }\end{array}$ \\
\hline NEGRA & ¡Resa! \\
\hline VENTERA & ¡Vete a los estabros! \\
\hline NEGRA & $\begin{array}{l}\text { ¡Que te reba ra riabros, } \\
\text { si robas pobre richados! }\end{array}$ \\
\hline VENTERA & Bien, son más de cien ducados. \\
\hline NEGRA & $\begin{array}{l}\text { ¡Ra mara bebites bino! } \\
\text { ¡Roba ra pobre mequino! (vv. 253-263) }\end{array}$ \\
\hline
\end{tabular}

Cuando despierta, el huésped pobre reclama a la ventera que le han robado y ella llama a la justicia y le acusa de no haber pagado sus deudas en la venta. Una vez que llega el alguacil, la ventera compra su inacción a cambio de un vaso de vino. La pieza termina con la entrada de un diablo «muy feroz» que viene a ajustar cuentas a la ventera y con las lágrimas de la negra que se duele por su ama y se alegra de no haber querido colaborar en el robo:

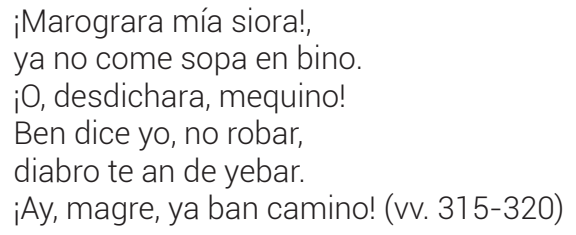

Por tanto, tenemos aquí un caso en que la esclava negra sirve a su ama, sí, y está dispuesta a colaborar en la buena marcha del negocio, pero no a cualquier coste, y cuando la ventera sin escrúpulos quiere robar al más pobre de sus huéspedes, la negra muestra su disensión y no colabora, aunque esa actitud le traiga maltrato verbal. La pieza termina finalmente con el establecimiento de la justicia personificada en el diablo que viene a castigar, ya que la justicia humana ha sido comprada por un vaso de vino. Este desenlace aporta el didactismo de la obra.

Coetáneas con las de Sánchez de Badajoz son las negras de Jaime de Huete. Se conserva una edición datada entre 1528-1535 de la obra teatral Tesorina en la que inserta este personaje ${ }^{11}$. Su editora moderna sitúa esta obra entre las «de corte celestinesco», recogiendo así toda una tradición crítica. Es ya una pieza extensa, que se aproxima a los 3000 versos de la comedia nueva con sus 2651 versos distribuidos en un introito y cinco jornadas irregulares en cuanto a la distribución de versos.

Conocemos rasgos del carácter de la esclava negra de Tesorina, Margarita, antes de que salga a escena. Frente a la comicidad que parece consustancial a la aparición de este tipo, a la negra de Huete la presentan otros criados con muchas 
reticencias como mujer de mal carácter. Además, dan con toda claridad sus señas de esclava:

$\begin{array}{ll}\text { TESORINO } & \begin{array}{l}\text { Pero quiérote avisar, } \\ \text { hablando con ti a la rasa, } \\ \text { que te has mucho de guardar } \\ \text { de una esclava que hay en casa. }\end{array} \\ & \text { Ya lo sé, } \\ \text { piNEDO } & \begin{array}{l}\text { con Citeria desta cosa } \\ \text { muy avisado quedé } \\ \text { ques bestia muy maliciosa. }\end{array}\end{array}$

Su presencia en el tablado se retrasa hasta la jornada quinta de la obra, pero en ella su actuación se prolonga intercalada en todos los versos, entre el 2033 y el 2651, con un total de 27 intervenciones, las cuales nos presentan su función de acompañante fiel de su señora. Sale a escena llamada por Timbreo y Sircelo, amo y mozo respectivamente, que regresan de un viaje alabando las mujeres y las tierras de Aragón, y denostando las de Castilla. Nada bueno en el trato anuncia la llamada a la negra: «llama essa esclava maldita» (v. 2074). Margarita sale a escena llorando y con lengua cerrada, ininteligible para los dos hombres que tratan de saber qué ocurre: «¿Entiéndesla tú, Sircelo?» pregunta Timbreo a lo que el mozo responde que no. Lo que la negra Margarita explica entre lágrimas parece ser la salida de su ama de casa mientras ella dormía sin que sepa su destino y su preocupación por este hecho: «estar mi xempre dormendo / y no hayar quando xpertaro» (vv. 2093-2094). La difícil lengua de la esclava, entrecortada además por las lágrimas durante buena parte de los versos, sulfura a los hombres, que no se recatan en el maltrato verbal: «doña perra» (vv. 2096 y 2140), «iQuán çuzio y torpe animal!» (v. 2128), «borracha» (v. 2133), entre otras expresiones. Los insultos contrastan con la comicidad que produce la mala comprensión del lenguaje por parte de los dos hombres, el cual, por otra parte, el público podía más o menos interpretar:

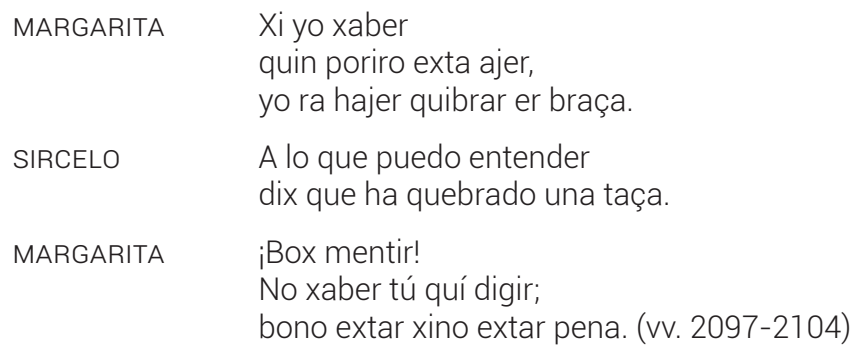

Pero interesa marcar la existencia de ciertos quiebros sicológicos, pues los hombres, que necesitan saber dónde han ido las mujeres, al ver que la presión de sus palabras y actitudes no hacen mella en la esclava, cambian de registro y Timbreo se dirige a ella de forma mucho más afectuosa a medida que transcurren los 
versos: «Calla, hija, Margarita / ¿qués de tu dueña y Citeria?» (vv. 2205-2206). La respuesta a esta pregunta le permite saber por boca de la esclava que salieron de la casa: «xi foron di caja empejo / y dixaron porta uberta» (vv. 2213-2214), con lo que el padre ve el honor familiar en peligro y exclama preferir la muerte:

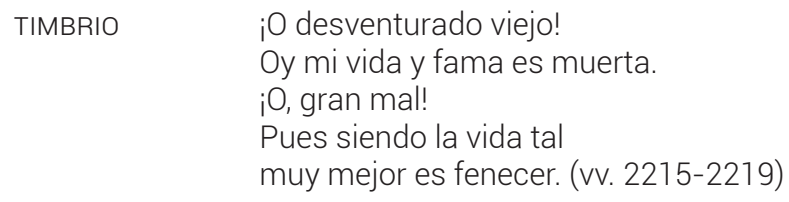

Por tanto, lo visto hasta ahora nos presenta a través de sus palabras a una esclava fiel que lamenta con lágrimas y gritos la desaparición de su ama y su preocupación por este hecho.

Una segunda fase en sus relaciones con personajes de esta jornada quinta la marca la entrada en escena del pastor de Timbreo, Giliracho, en el v. 2357, el cual, frente a la actitud fiel de la negra esclava, se muestra mucho menos afectuoso con las mujeres desaparecidas. Cuando no quiere hablar a su amo de dónde están las mujeres recibe la réplica airada de Margarita: «Tú xaber y digir no» (v. 2369) lo que provoca su ira y el ataque verbal: «iValgaos el diablo, morruda!» (v. 2370) que se desplaza a lo largo de los versos que siguen en esta jornada con improperios como «gargajo puesto en pared» (v. 2376), «doña puerca» (vv. 2372 y 2540), «doña çuzia lagañosa» (v. 2410), «carabagenta, sarnosa» (v. 2412), «lendrosa» (v. 2485), «negra» (v. 2616), «vellacaza» (v. 2622), «doña putonaza» (v. 2625) y aceradas puIlas: «iMala postema os reviente!» (v. 2546). Contra él van también los improperios de la negra, los cuales nunca dirigía a su amo, como es natural: «patanax, viyaca, borde» (v. 2414), «viyaco» (v. 2532), «don boraxo» (v. 2547) e incluso el ataque físico de la mujer, enfadada por la falta de fidelidad del pastor que oculta dónde vio a las mujeres. «Dale, xux, / te yuro por esta crux / qui yo te quibraré el dente» (vv. 25422544). Y parece que, en efecto, la negra pega al pastor, a juzgar por sus palabras: «Veis que me ha dado en el oxo / la cachonda, vil, bagassa?» (vv. 2550-2551). Esta actitud belicosa de la negra marca un antes y un después entre las presentaciones que el teatro hace de este personaje, si bien aquí está subordinada a la función que ya señalamos de acompañamiento fiel de su ama. La obra termina con Sircelo poniendo paz entre ellos. La amplitud del pasaje de Jaime de Huete en su Tesorina con presencia de la esclava negra, permite ver uno de los personajes más logrados y originales de este teatro del siglo $\mathrm{XVI}^{12}$.

Algo más tardía es la Tercera parte de la tragicomedia de Celestina (1536) de Gaspar Gómez de Toledo, que presenta en el Aucto V a la negra Beruga la cual interrumpe la conversación entre Polandria y Poncia con su llegada. Pero pronto se sabe que escuchaba antes de entrar, pues Poncia se lo echa en cara: «si tú por ser maliciosa te paras a escuchar, y tras oyes, ¿de qué te enojas conmigo?» (p. 116). El peligro de que la negra cuente la conversación a su señora Paltrana preocupa a las dos mujeres, que se ganan su silencio regalándole una cofia y prometiéndole

12. Errazu, 2002, p. XV y n. 8. 
nuevos presentes bajo palabras fingidas: «porque veas el amor que te tengo» ( $p$. 117). El efecto que consiguen es el deseado, pues dice Beruga: «A vox y a la siñora Porandra, muchas gracias, que a mi cayar y xeruir extax merxedes» (p. 117).

\section{La negra enamorada de un blanco}

La función de acompañante toma nuevas modalidades en las negras que salen a escena tratando de prestar su ayuda a un señor, si bien pronto descubriremos que lo que le mueve no es sólo el interés por atajar la violencia en escena.

Sucede así en la farsa La hechicera, de Diego Sánchez de Badajoz. En este caso, la mujer negra innominada que actúa en la obra entre un total de siete interlocutores, se encuentra a caballo entre cierta función cómica y pacificadora pero, sobre todo, es uno de los raros ejemplos que se encuentran en el teatro del XVI de mujer que busca el contacto físico con un hombre de posición social superior a la suya y al que admira y quizá ama. En La hechicera su pasaje está en la parte inicial de la pieza, entre los vv. 33-96, y establece un dialogismo con el galán que entra en escena quejoso de la crueldad con que le trata su amada, presentado en clave de lenguaje de amor cortés. En su desesperación ante el desprecio de su dama a todos los intentos de ganarla, decide:

$$
\begin{aligned}
& \text { Pues no puedo, con biuir } \\
& \text { seruille en cosa que acierte, } \\
& \text { quiérole ofrecer la muerte: } \\
& \text { quiças le podré seruir. (vv. 61-64) }
\end{aligned}
$$

Y, en efecto, el final de su parlamento termina con un gesto violento: «iSal acá, cruel puñal / y acaba vida tan ciega!» (vv. 71-72). Es precisamente en ese instante cuando, frente a la llegada de personajes míticos en otras obras, como es la Égloga de Fileno, Zambardo y Cardonio de Gil Vicente, sale aquí a escena «una negrilla y arremete con él a tiralle el puñal, diciendo:

$$
\begin{aligned}
& \text { ¡Sesú, Sesú. maraviyo! } \\
& \text { ¿Por qué goyas tan bonino? } \\
& \text { Saque ro prito marino, } \\
& \text { sorta, resa ra cosío. (vv. 73-76) }
\end{aligned}
$$

Y, tras un forcejeo, la acotación indica: «Aquí se abraça la Negra con el Galán y llega su cara con la dél, halagándolo». Alguna frase de ella parece demostrar que lo que le mueve no es sólo lealtad al galán, por ejemplo, cuando se dirige a él como «mi corazón y mi bira» (v. 82). Pero sobre todo sabemos de su actitud a través de la reacción del hombre: 
Que ella confirma: «iPariós, vos nunca me matas / aunque me das binte quesos!» (vv. 87-88). Pero la negra, que se ve rechazada, se aparta de él y le abandona a su suerte. Es, pues, un ejemplo de audacia extrema que resulta difícil de encontrar en otras obras, incluso del siglo siguiente con una trama dramática más compleja.

Cierta audacia, aunque más limitada pues se da entre personajes de posición social homogénea, podemos verla en el paso Eufemia de Lope de Rueda; en concreto, en su escena séptima, penúltima de la obra. La dramatización tiene en ella dos personajes: el lacayo Polo y la negra Eulalla. El inicio de la escena permite pensar al receptor que se trata de un verdadero amor del hombre por la criada: «Acá me quiero andar siguiendo mi planeta: que si aquesta mi Eulalla se va conmigo como me tiene prometido, yo soy uno de los bienaventurados hombres de todo mi linaje» (p. 100). La cantilena de ella en la ventana, el llamar de él, el recato con que contesta al no saber que es Polo quien llama parecen mostrar una mujer que cuida su honor: «¿Paréscete vos que so sa bon xemplos a la ventana de un dueña honradas recogidas como yo, facer aquella cortesía a taloras?» (p. 101) y de nuevo, pocas líneas más tarde se hace llamar «fija de la hombre honrados» (p. 101). También la actitud de él parece la de quien corteja: «Señora mía, por una pieza como vuesa merced aun es temprano para servilla» (p. 102) y aún más cuando ella le dice que su amo quiere casarla y él recuerda promesas antiguas: «¿No me has prometido de salirte conmigo?» (p. 103) y más adelante: «¿Y la palabra, señora, que me has dado?» ( $p$. 103). El lacayo insiste, en fin, en sus amores: «No te podría yo dejar, que primero no dejase la vida» (p. 103). Pero la criada Eulalla se muestra inaccesible con disculpas varias entre las que están su obligación para con su amo: «na forza ne va nerrechos se pierde» (p. 103), esto es, «do fuerza corre, derecho se pierde» o un nuevo refrán: «honra y barbechos no caben los sacos» (p. 103). También objeta no querer salir de su tierra y, ante la insistencia de Polo, rebate su propuesta con palabras gruesas: «iAh, traidoraz! ¡Dolor de torsija que rebata to lo rombres. A otro güeso con aquese perro, que yo ya la tengo rosegadoz» (p. 103), en relación con su mala experiencia con los hombres. Resulta también interesante saber con quién pretenden casarla: un pastor de cabaña o «cagañero» o un boticario. Por un momento parece ceder Eulalla a cambio de que su enamorado le regale unas monas y un papagayo ( $p$. 104), obsequios ambos de damas que demostraban su poder en la posesión de animales exóticos como estos en la España de la época.

Sin embargo, tras esta escena de requerimientos, la situación cambia por completo y el espectador pudo ver hasta qué punto llegaba la hipocresía de ambos en su relación. Con la excusa de ir a ver un ajusticiamiento sale Polo y, al quedarse sola la negra, exclama: «iAy, mal logradoz! Por ciertos que me pesas como si no fueras mi fijo; mas si marinas busca, tome lo que baila» (p. 105), que el editor anota: «Pues Marina bailó, tome lo que ganó», donde se aprecia el interés que movía a la mujer. Pero tampoco era mucho mejor la actitud del lacayo que al salir de la escena indica: «iPese a tal con la galga! Yo la pienso vender en el primer lugar diciendo que es mi esclava, y ella póneseme en señoríos» (p. 105). Descubrimos así el verdadero interés del lacayo que pensaba desde el principio conseguir beneficio de la venta de la criada negra a la que haría pasar por su esclava. Todavía termina la jornada 
con la mujer llamándole desde la ventana y consiguiendo de él nuevos -y falsospiropos sobre su apariencia externa.

Tenemos de nuevo una negra engañada por un blanco, en este caso no un galán sino un lacayo de posición social semejante a la suya. Cada uno espera obtener un beneficio material del otro, aunque no son comparables ni el fin ni los medios, pues lo que espera lograr la negra son regalos materiales mientras el lacayo no tiene empacho en decir que su fin es conseguir dinero a cambio de la venta de la mujer, a la que además hará pasar por esclava. Relaciones difíciles, sin duda, en las que tampoco ella se fía por completo de las proposiciones del supuesto enamorado, parece que engañada por otros antes.

\section{La negra displicente con su enamorado negro}

En cuanto a la negra Boruca, se presenta en la II Cena de la Segunda Celestina de Feliciano de Silva (1534) como una mujer que se sabe cortejada por el negro Zambrán, criado de Quincia, del que se burla:

$\begin{array}{ll}\text { QUINCIA } & \text { Boruca, hermana, ¿venir mandar algo para Zambrán? } \\ \text { BORUCA } & \text { Ha, ha, ha. } \\ \text { QUINCIA } & \text { ¿De qué reír Boruca? } \\ \text { BORUCA } & \text { Extar mucho me namorado Zambrán. } \\ \text { QUINCIA } & \text { Por esso mejor. } \\ \text { BORUCA } & \text { Dar al diablo, xeñora, que extar muy veliaco, que arremeter } \\ & \text { a mí extotro día a querer bexar como un perro. (p. 132). }\end{array}$

Su personaje no volverá a aparecer hasta la VI Cena en que se encuentra el parlamento más largo con presencia de los negros. Feliciano de Silva la hace salir a escena como quien llega a interrumpir el cortejo de Pandulfo a Quincia y su entrada proporciona cierto margen a esta mujer para escapar de las presiones de su enamorado. Parece que Boruca encomendó a Quincia un recado para su enamorado y le pregunta por él, a lo que Quincia responde que Zambrán no está contento y la acusa de «veliaca» y de no quererle lo suficiente. Cuando Quincia le pide una respuesta para el negro, ella continúa con sus burlas y recriminaciones por la mala vida que él lleva:

$\mathrm{Ha}$, ha, ha; dezir que dezir a mí qu'extar veliaco y que andar en puterionex, que a mí xaber salir ayer de la puterixa de caxa de Palanax, que no dexir despóx jurax a Dux mucho te quero, mucho te quero. (p. 162)

Ante la salida a escena de Zambrán, Boruca trata de huir para no encontrarse con él, pero no lo consigue y comienza un rápido diálogo en que ella le rechaza:

ZAMBRÁN ¿Por qu'extar tan veliaca que querer fugir de mí?

BORUCA Andar, andar para Polanax. 
ZAMBRÁN Embidia extar éxa e bien parescer a mí, andar acá amorex y nuer ${ }^{13}$ enojo. Jurax a Dux máx quere a ti que a todas, dexar ox celox.

BORUCA

Andar con el diabro; dexar a me, xeñora Quincia. Tomar, don vellaco, porque llegar a me. (p. 163)

Zambrán intenta abrazarla y se detiene ante la negativa de su negra amiga.

$\begin{array}{ll}\text { ZAMBRÁN } & \begin{array}{l}\text { ¡Oh, corpo de Dux, con talex burlax! Jurax a Dux que } \\ \text { te tengo de abraçar aunque no querer. }\end{array} \\ \text { BORUCA } & \text { Dexarme, veliaco, dexarme. } \\ \text { ZAMBRÁN } & \text { Ora pox, perdonarme y a mí dexar. } \\ \text { BORUCA } & \text { Ora xí perdonar, andar con el diabro. } \\ \text { ZAMBRÁN } & \text { Ora pues, a mí andar a tu caxa exta noche. } \\ \text { BORUCA } & \text { Ora andar, que vox pagar a me. (p. 163) }\end{array}$

Boruca acude a la complicidad con su señora, para que no permita entrar al negro en su casa de noche, como éste pretende, y también a la de Pandulpho al que pide que le lea la carta que ha recibido de Zambrán en la que le pide matrimonio. No deja de llamar la atención esta carta 'entre negros' que es una muestra más de «la trivialización de la convención cancioneril y su forma de concebir las relaciones amorosas» ${ }^{14}$, así como de la entrada de la convención de la carta y sus raíces cultas en un mundo social que le es ajeno por completo. Quizá también por ello, la carta no surte el efecto deseado y Boruca se burla del emisor, después de oírla, ya que ella no sabe leer:

Gualá, estar ben excrita, max a me no se me dar nada máx de para burlar y paxar tempo, que extar un bovo Zambrán. Dexer, hermana Quincia, que dexar dextax boveríax y dexar amore conex, que no aprovechar nada. (p. 164)

Como se puede ver y aunque se trate de una amor paralelo en raza, y parece que también en situación social, la negra Boruca se muestra displicente ante las propuestas amorosas de su enamorado Zambrán; por cierto que en ningún momento llegamos a saber si son criados esclavos o libres. Esta vez la actitud será más franca entre la pareja que la vista antes entre el lacayo Polo y la negra Eulalla, pero tampoco la relación parece llegar a buen término, sino que se trata más bien de crear una situación cómica en la pieza, apoyada en el lenguaje de ambos, que ocupa un espacio limitado en las cuarenta Cenas de la Segunda Celestina. 


\section{La negra y su función catequética}

Entre las piezas teatrales que incorporan la figura de la negra se encuentran, como se ha dicho, las de Diego Sánchez de Badajoz. Sin que sea posible conocer el espacio de representación de sus Farsas (Díez Borque, 1978, pp. 44-53) algunas de ellas estuvieron vinculadas, sin duda, con fiestas como Pascua y Corpus, si bien con espectacularidad limitada. La figura de la negra tiene, además de la función cómica que le es inherente, una función catequética en obras como la Farsa teologal.

En relación con esta última, su personaje está al servicio de mostrar la amplitud de la fe a diversos grupos sociales y, además, sirve de pretexto para que se exponga la esencia de los sacramentos del bautismo y del matrimonio y, de paso, se haga un recorrido catequético sobre ellos. El que podría llamarse Paso de una negra, un pastor y un soldado muestra la figura de la negra sin nombre, criada de un soldado violento, que se presenta en escena cantando y tañendo un pichel mientras anuncia el nacimiento de Cristo. Su entrada en escena sirve para que el teólogo dé cuenta de la universalidad de la buena nueva: «iO, Sacro Verbo divino, / o, misterios eternales, / que aun a los negros bozales / manifiestas tu camino!» (vv. 769-772) ${ }^{15}$. La referencia a los sacramentos de los que antes se habló se encuentra en la última parte de la pieza. Observemos cómo se inserta en la conversación la doctrina del matrimonio, entre burlas y veras. Surge cuando el cura descubre que la negra que acaba de llegar no está bautizada y exclama: «iEntre christianos, y mora!» (v. 1032) y trata de asegurarse preguntándole: «¿Tú vístete rociar / del lavatorio divino?» a lo que ella responde: «Nunca me raba con bino, / ma con agua, sí rabar» (vv. 1035-1036) y aclara el cura: «Convienen virificar / esta cosa de cimiento, / porque aqueste sacramento / dos vezes no se a de dar» (vv. 1037-1040). Y es que, en efecto, convenía quizá dejar claro ante el auditorio parte de la doctrina esencial del Bautismo como es el hecho de que imprime caracter en el bautizado, por lo que no se debe repetir. Aprovecha ahí el cura para continuar la explicación sobre los siete sacramentos. De nuevo es la negra quien da pie con su negativa a casarse con el pastor que la requiebra, a recordar la enseñanza sobre el matrimonio, cuando protesta: «Fransico estar mi mariro, / ¿cómo casa? ¿Ya etar mueto?» (vv. 142-143) a lo que responde el cura: «En esso no me entremeto, / non potest vivente viro» (vv. 144-145). Y es que, en efecto, es el personaje cómico de la negra el que facilita una vez más la buena entrada del mensaje catequético.

\section{El disfraz de negra como eje de la burla}

La negritud ocupa también un lugar destacado como protagonista de burlas. En la Floresta de engaños de Gil Vicente se localiza un pasaje al que la crítica ha denominado el entremés de la negra 'paneteira'16 representado -como la obra entera- ante el rey don Juan III de Portugal en Évora el año 1536. La función del disfraz de negra en esta obra es provocar comicidad y rebajar la figura del juez, licenciado 
en París y hombre de confianza del rey Telebano, al puesto más bajo de la escala social de su tiempo: mujer, esclava y negra, con el fin de conseguir el amor de la que cree una joven antes de conocerla. La burla se sitúa entre los vv. 498 y 748 , y viene precedida por la conversación del juez, al que se llama «Doutor Justiçia Maior», con el mismo rey. Interesa destacar el bilingüismo, por el que el juez se expresa en castellano mientras las mujeres lo hacen en portugués. Un juez de sesenta y seis años (v. 516) recibe la visita de una moza que llega a pedir consejo, pero de modo inmediato él la corteja con disgusto por parte de la joven, y se insinúa de forma abierta:

$\begin{array}{ll}\text { DOUTOR } & \text { ¿Y qué me daréis en pago? } \\ \text { MOÇA } & \text { ¿E tanto sois meu amigo? } \\ \text { DOUTOR } & \text { Yo no quiero } \\ & \text { de vos plata ni dinero } \\ & \text { mas privar con vos por cierto } \\ & \text { en lugar mucho secreto } \\ & \text { por deciros cuánto os quiero. (vv. 540-546) }\end{array}$

Pero la propuesta de la joven cambia su interés por ella en otro por su señora. Es precisamente ahí cuando la moza urde el engaño: "Oh como hei d'enganar / um Doutor que se enganou» (vv. 564-565) y poco después se burla por anticipado: «negro contentamento / o negro Doutor terá» (vv. 569-570). Y, en efecto, muy risible es la escena en la que le despoja de todos sus aperos: «luvas, sombreiro, / beca de veludo» (vv. 595-596) y le viste de negra: «e vesti esra fraldiha / e ponde esta beatilha / e fazei que peneirais» (vv. 601-603). Quien entra, en realidad, es una vieja, a la que la joven descubre su venganza: «Eu o pus dessa maneira / porque me falou d'mor» (vv. 672-673), lo que trae la risa de la vieja: «Jesu e quem viu doutor / em fraldas de panadeira?» (vv. 674-675). El doctor, descubierto el engaño, se asombra y decide ocultar la humillación:

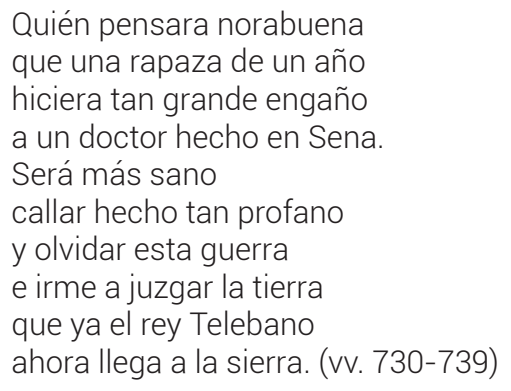

Tenemos así un juez burlado que ha consentido el disfraz de negra para lograr un beneficio sexual que no se llevará a efecto. No sabemos si este pasaje fue uno de los que levantó las sospechas de la Inquisición, por cierto que instaurada en Portugal el mismo año que se representó esta obra, y con Gil Vicente como primer damnificado. La obra fue censurada no sólo en Portugal sino también en España y 
su título aparecía en el índice de 1551, Rol dos libros defesos pelo Cardeal-Infante Inquisidor Geral nestes reinos, publicado en Évora, y en el Cathalogus librorum qui prohibetntur hoc anno 1559, en Valladolid. Sin embargo, en la Compilaçam de obras vicentinas impresa en 1562, de la que consta haber sido examinada por censores, no se aprecian cambios, pero ya los hay en la edición de 1586 en la que se omiten cinco versos y se alteran otros siete. Algunos afectan a nuestro pasaje, por ejemplo, el segundo verso que pronuncia el doctor: «iOh, entrad acá, señora, / mi sagrado paraíso!» (vv. 523-524) dirigido a la moza, cambia tras la censura en «porque me matais com isso». Una vez más se constata que la censura afecta a expresiones concretas y escapan de ella episodios de mayor complejidad.

\section{CONCLUSIÓN}

El recorrido por estos textos de fines del siglo xv pero, especialmente, del siglo $X V I$, nos muestra el tratamiento de la figura de la negra por parte de autores tan variados como Anrique de Mota y Rodrigo de Reinosa -en ambos casos textos poéticos con una fuerte carga de dramaticidad - y, especialmente, en las obras de dramaturgos del XVI como Jaime de Huete, Feliciano de Silva, Gaspar Gómez de Toledo, Gil Vicente, Diego Sánchez de Badajoz y Lope de Rueda. Un repertorio creemos que lo suficientemente amplio para observar cómo se traspone a la literatura quien era, sin duda, una figura muy característica de la sociedad del siglo XVI: la negra esclava o, al menos, la negra criada, pues en varios casos no consta de forma explícita su condición.

De la negra como personaje del teatro del siglo XVI llama la atención, sobre otros rasgos, la seguridad que manifiesta en sí misma, tanto en su porte y en el trato con sus amos y amas como en su capacidad para mover la intriga hacia los fines deseados por el dramaturgo y, desde luego, en la gracia de su lenguaje y de sus movimientos de canto y baile, cuando aparecen integrados en la presentación, que no es siempre. De la confianza en su persona, en ocasiones originada por haber sido preparada en casas importantes, se desprende cómo a menudo la violencia verbal e incluso física con la que comienzan tratándola algunos de los personajes teatrales, no tarda en sucumbir ante su resistencia y su capacidad de dar la vuelta a una situación en su beneficio. Su saber hacer muestra también el interés que algunos hombres manifiestan por ella, pues se la presenta en escena deseada en ocasiones por varios de forma simultánea y con la decisión de aceptar o no en sus manos. Aunque en algunos casos hay ironía y deseo de aprovecharse de ella, incluso de venderla como esclava, en la mayoría de las ocasiones la negra sale airosa y es ella quien acepta o -en la mayoría de los casos- desprecia a quien la corteja, ya sea de raza negra o incluso blanca. No deja de sorprender ver a la negra buscando el contacto físico con un hombre blanco de posición superior a la suya, lo que no llegará a buen fin.

La negra tiene su honor y lo defiende en no pocos momentos dramáticos sin dejar que se mancille su honra ni su buena fama, aunque sea un poderoso quien trate de hacerlo Recurrirá con ingenio a astucias varias para detener la acción vil 
de quien intenta acusarla de modo injusto, hasta poner a su señor en ocasiones en una situación de fuerte debilidad social - con acusaciones falsas incluso de acoso sexual-, lo que le hará cejar en sus malos propósitos con la criada negra.

Conocedora de los secretos de sus amos, sabe utilizar ese poder para salir ilesa de las trampas que en ocasiones intentan tenderla y muestra su fortaleza ante ellos a través de su silencio o de su capacidad de desvelar pasajes oscuros de las vidas de sus señores. Fiel a sus amas cuando lo merecen, no duda en exponerse por ellas al máximo, pero tampoco permite que la involucren en sus juegos sucios, cuando los hay, y en esos momentos se separa con independencia de ellas y manifiesta una fuerte autonomía.

La negra es, en fin, todo menos un personaje agobiado o perjudicado por el peso de su negritud, como en ocasiones se ha presentado a este personaje dramático, si bien las cábalas no se hacían únicamente sobre la 'negra' sino que se referían a ambos sexos y revisaban su figura en especial en el teatro del siglo XVII ${ }^{17}$. El análisis detallado que hemos hecho de los textos del siglo XVI con presencia de mujeres negras, de su forma y función en la práctica poética y, en especial, en la teatral del Renacimiento, permite afirmar que las negras del teatro de ese periodo no se sienten inferiores y saben que en muchos casos son ellas las que tienen las claves para resolver una situación, se muestran orgullosas de su presencia y habilidades, de la riqueza de sus tierras de origen y de la enseñanza que han recibido en buenas casas. Son conscientes, en resumen, de que están dotadas de la sabiduría de la vida y de la experiencia para solucionar situaciones que otros no podrían, por blancos que fueran.

Los pasajes de negra, micro-textos en las obras en que se insertan, guardan relaciones estrechas con la trama en que se encuadran y son un contrapunto de interés con otros personajes y situaciones, de modo que su función resulta significativa. La negra es un personaje poderoso entre las bambalinas teatrales, que encamina sus pasos hacia tipos que alcanzarán protagonismo en el teatro del siglo $\mathrm{XVII}$.

\section{BIBLIOGRAFÍA}

Andújar Castillo, Francisco. «Sobre las condiciones de vida de los esclavos en la España moderna. Una revisión crítica», Chronica Nova, 26, 1999, pp. 7-36.

Baranda Leturio, Consolación, «Las hablas de negros. Orígenes de un personaje literario», Revista de Filología Española, 69, 3-4, 1989, pp. 311-333.

Castellano, Juan R., «El negro esclavo en el entremés del Siglo de Oro», Hispania, $44,1,1961$, pp. 55-65.

17. «En el teatro español del Renacimiento y el Barroco la figura del negro aparece de tres maneras. Unas veces el negro es representado como negación de la humanidad. En otras es protagonista del intento de borrar su color negro y lo que ello significa, la presencia del negro en la sociedad como diferencia y como ser en la historia. Finalmente, el personaje negro aparece reclamando la libertad frente a la sociedad que lo esclaviza y que niega su presencia y su memoria en la historia» (Fra Molinero, 2014, p. 11). 
Cátedra, Pedro, «Lope de Rueda y el Coloquio de Gila», en «Tres coloquios pastoriles» de Juan de Vergara y Lope de Rueda (Valencia, 1567), San Millán de la Cogolla, Cilengua, 2006, pp. 389-465.

Cortés López, José Luis, La esclavitud negra en la España peninsular del siglo XVI, Salamanca, Universidad de Salamanca, vol. 69, 1989.

Fra Molinero, Baltasar, La imagen de los negros en el teatro del Siglo de Oro, Madrid, Siglo XXI, 1995.

Fra Molinero, Baltasar, «Los negros como figura de negación y diferencia en el teatro barroco», Hipogrifo, 2, 2, 2014, pp. 7-29.

Gómez de Toledo, Gaspar, Tercera parte de la tragicomedia de Celestina, ed. Mac E[ugene] Barrick, Philadelphia, University of Pennsylvania Press, 1973.

Granda, Germán de, «Sobre el origen del "habla de negro" en la literatura peninsular del Siglo de Oro», en Estudios linguisticos hispánicos, afrohispánicos y criollos, Madrid, Gredos, 1978, pp. 216-233.

Huete, Jaime de, Tesorina. Vidriana, ed. Ángeles Errazu, Zaragoza, Prensas Universitarias de Zaragoza, 2002.

Lawrence, Jeremy, «Black Africans in Renaissance Spanish literature», en Black Africans in Renaissance Europe, ed. T.F. Earle y K.J.P. Lowe, Cambridge, Cambridge University Press, 2005, pp. 70-93.

Lobato, María Luisa, La jácara en el Siglo de Oro español: Literatura de los márgenes, Madrid/Frankfurt, Iberoamericana/Vervuert, 2014.

Lobato, María Luisa y Alain Bègue (ed.), Literatura y música del hampa en los Siglos de Oro, Madrid, Visor Libros, 2014.

Moro, Laura Puerto, Obra conocida de Rodrigo de Reinosa, San Millán de la Cogolla, Cilengua, 2010.

Mota, Anrique da, D'Anrique da Mota a um Créligo sobre ũa pipa de vino que se Ihei foi polo chão, e lamentava-o, en Cancioneiro General de García de Resende. Edición de 1848 digitalizada por la Biblioteca Nacional de España, ed. E.H.v. Kausler, Stuttgart, Gedruckt auf Kosten des literarische Vereins, 1848, vol. III. Disponible en línea: <http://bdh-rd.bne.es/viewer.vm?id=0000004782\&page=1> [9/1/2017].

Profeti, Maria Grazia, «ll negro nella commedia aurea», en La maschera e l'altra, ed. Maria Grazia Profeti, Florencia, Alinea, 2005, pp. 1000-1016.

Rueda, Lope de, Eufemia y Armelina, ed. Fernando González Ollé y Vicente Tusón, Salamanca/Madrid/Barcelona/Caracas, Anaya, 1967, pp. 55-112.

Sánchez de Badajoz, Diego, La hechicera, en Farsas, ed. José María Díez Borque, Madrid, Cátedra, 1978, pp. 485-495. 
Sánchez de Badajoz, Diego, Recopilación en metro (Sevilla, 1554), ed. Frida Webber de Kurlat, Buenos Aires, Universidad de Buenos Aires, 1968.

Santos Morillo, Antonio, «Caracterización del negro en la literatura española del

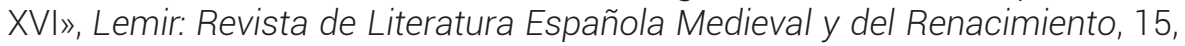
2011, pp. 23-46.

Silva, Feliciano de, Segunda Celestina, ed. Consolación Baranda, prólogo Fernando Arrabal, Cátedra, 1988.

Stoichita, Victor I., «La imagen del hombre de raza negra en el arte y la literatura españolas del Siglo de Oro», en Herencias indígenas, tradiciones europeas y la mirada europea: actas del Coloquio de la Asociación Carl Justi y del Instituto Cervantes de Bremen, ed. Helga von Kügelgen Kropfinger y Gabriele Schulze, Madrid/Frankfurt, Iberoamericana/Vervuert, 2002, pp. 259-290.

Swiadon Martínez, Glenn, «Los villancicos de negro y el teatro breve. Un primer acercamiento», en La literatura popular impresa en España y en la América colonial: formas y temas, géneros, funciones, difusión, historia y teoría, dir. Pedro Manuel Cátedra García y María Sánchez Pérez, ed. Laura Puerto Moro, Eva Belén Carro Carvajal y Laura Mier Pérez, 2006, pp. 161-168.

Tobar, María Luisa, «Los disfrazados de mujer en la Floresta de engaños de Gil Vicente», en Los albores del teatro español: actas de las XVII Jornadas de Teatro Clásico, Almagro, ed. Felipe B. Pedraza Jiménez y Rafael González Cañal, 1995, Ciudad Real, Universidad de Castilla-La Mancha, pp. 139-154.

Vicente, Gil, Floresta d'Enganos, en As obras de Gil Vicente, dir. José Camões, Lisboa, Centro de Estudos de Teatro da Facultade de Letras da Universidades de Lisboa/Imprensa Nacional-Casa da Moneda, 2002, vol. I, pp. 479-515.

Weber de Kurlat, Frida, «El tipo cómico del negro en el teatro prelopesco: fonética», Filología, 8, 1962, pp. 139-168.

Weber de Kurlat, Frida, «Sobre el negro como tipo cómico en el teatro español del siglo XVI», Romance Philology, 17, 2, 1963, pp. 380-391. 
